\title{
Accurate inference of shoot biomass from high-throughput images of cereal plants
}

\author{
Mahmood R Golzarian', Ross A Frick², Karthika Rajendran³, Bettina Berger ${ }^{3}$, Stuart Roy ${ }^{3}$, Mark Tester ${ }^{3}$, \\ Desmond S Lun ${ }^{1,4^{*}}$
}

\begin{abstract}
With the establishment of advanced technology facilities for high throughput plant phenotyping, the problem of estimating plant biomass of individual plants from their two dimensional images is becoming increasingly important. The approach predominantly cited in literature is to estimate the biomass of a plant as a linear function of the projected shoot area of plants in the images. However, the estimation error from this model, which is solely a function of projected shoot area, is large, prohibiting accurate estimation of the biomass of plants, particularly for the salt-stressed plants. In this paper, we propose a method based on plant specific weight for improving the accuracy of the linear model and reducing the estimation bias (the difference between actual shoot dry weight and the value of the shoot dry weight estimated with a predictive model). For the proposed method in this study, we modeled the plant shoot dry weight as a function of plant area and plant age. The data used for developing our model and comparing the results with the linear model were collected from a completely randomized block design experiment. A total of 320 plants from two bread wheat varieties were grown in a supported hydroponics system in a greenhouse. The plants were exposed to two levels of hydroponic salt treatments $(\mathrm{NaCl}$ at 0 and $100 \mathrm{mM}$ ) for 6 weeks. Five harvests were carried out. Each time 64 randomly selected plants were imaged and then harvested to measure the shoot fresh weight and shoot dry weight. The results of statistical analysis showed that with our proposed method, most of the observed variance can be explained, and moreover only a small difference between actual and estimated shoot dry weight was obtained. The low estimation bias indicates that our proposed method can be used to estimate biomass of individual plants regardless of what variety the plant is and what salt treatment has been applied. We validated this model on an independent set of barley data. The technique presented in this paper may extend to other plants and types of stresses.
\end{abstract}

\section{Introduction}

Plant biomass is an important factor in the study of functional plant biology and growth analysis, and it is the basis for the calculation of net primary production and growth rate [1-4]. Depending on the available budget, accuracy required, structure and composition of the vegetation, and also different disciplines of plant biology, there are several techniques to measure plant biomass [5]. In the study of biomass of an individual plant, shoot dry weight is one of the acceptable measures. This method is typically used to estimate a plant's yield, but it is also an accurate measure of plant biomass.

\footnotetext{
* Correspondence: dslun@camden.rutgers.edu

'Phenomics and Bioinformatics Research Centre, Australian Centre for Plant Functional Genomics, School of Mathematics and Statistics, University of South Australia, Mawson Lakes, SA, 5095, Australia

Full list of author information is available at the end of the article
}

The conventional means of determining shoot dry weight (SDW) is the measurement of oven-dried samples. In this method, tissue is harvested and dried, and then shoot dry weight is measured at the end of the experiment. To investigate the biomass of a large number of plants, this method is very time consuming and labor intensive. Also, since this method is destructive, it is impossible to take several measurements on the same plant at different time points. Therefore, an imaging method has been proposed to infer plant biomass accurately as a non-destructive and fast alternative. The Plant Accelerator [6] and the High Resolution Plant Phenotyping Centre [7] in Australia, the Leibniz Institute of Plant Genetics and Crop Plant Research (IPK) in Germany [8], the Institute of Biological, Environmental and Rural Sciences (IBERS) in the UK [9], and PHENOPSIS system being built by the National Institute for 
Agricultural Research (INRA) in Montpellier, France [10], have established or are planning to establish advanced plant phenotyping facilities that each provide the capability of hundreds to thousands of plants to be automatically imaged from standard positions and then analyzed via image analysis programs every day.

Digital image analysis has been an important tool in biological research and also has been applied to satellite images, aerial photographs and macroscopic and microscopic images [11]. A relevant application of image analysis which has been used for decades is in the area of remote sensing forestry and precision agriculture in which the area of plant species cover and the biomass of the above-ground canopy are estimated from satellite and airborne images [12-20]. These techniques have found a recent application in estimating the biomass of individual plants in a controlled environment and also in the field. There have been only a few projects on the application of image analysis techniques to estimate above-ground biomass of an individual plant. In these, the projected shoot area of the plants captured on two dimensional images was used as a parameter to predict the plant biomass [1,15,21-25]. Except for predicting cereal plant biomass as a linear function of plant area, however, none of the methods described in the literature was developed explicitly for high throughput phenotyping facilities. A robust and accurate method is required for high throughput phenotyping.

An additional factor to consider is the level of salinity to which the plant has been exposed. Arid and semiarid agricultural lands such as those in Australia inevitably pose some levels of soil salinity, which is one of the major environmental stresses that significantly affects crop productivity. The crop plants are stressed when the high concentrations of salts in the soil make it harder for their roots to extract water [26,27]. Salinity seems to have some effect on wheat growth in terms of their morphology, physiology and anatomical changes [26,28-30]. The applied salt treatment on the plants in the simulates the effect of soil salinity on crop plants in an agricultural field. The linear model, the predominant method used to estimate plant biomass, shows biased estimation of plant biomass particularly for salt stressed plants.

The objective of the present study is to develop a generalized method to estimate the biomass of cereals from their projected shoot area on two dimensional images. We have developed a method that significantly reduces the bias in biomass estimation of stressed cereal plants, which is the main source of the estimation error. We have demonstrated that a model that uses mixed variables of plant area and plant age achieves this reduction and therefore the method we proposed can be used to compute accurately the biomass of cereal plants regardless of whether or not they are salt stressed. In order to generalize our method to cereal plants we tested our method on both wheat and barley datasets and achieved promising results.

\section{Methods}

\section{Image acquisition}

Plant images were captured using a LemnaTec 3D Scanalyzer (LemnaTec, GmbH, Wuerselen, Germany) at Australian Centre for Plant Functional Genomics (University of Adelaide, Waite Campus, Adelaide). Comparable imaging systems are also used in other phenotyping facilities. Three $1280 \times 960$ resolution RGB images were taken of every plant: one top view image and two side view images at a $90^{\circ}$ horizontal rotation. The images were stored in PNG format. In order to increase the accuracy of separating the background from the region of interest (plant region), a roughly uniform blue background was used and the plant pot was also wrapped in a blue paper tube at the time of imaging. To develop the model and ensure sufficient variation, a total of 320 wheat plants were used for this study. The plants were of two Australian bread wheat varieties, Krichauff and Berkut, grown under two salt treatments, 0 and $100 \mathrm{mM} \mathrm{NaCl}$. The bread wheat (Triticum aestivum L.) cultivars Berkut and Krichauff are quite distinct, and have different pedigrees. Berkut comes from CIMMYT, Mexico and Krichauff is a southern Australian commercial cultivar. They have been selected as diverse parents of a mapping population, which have been identified to have significant variation in salinity tolerance traits, one of which has even been mapped in a large genetic study, published recently [31].

In terms of salinity, $100 \mathrm{mM}$ salinity is a moderate level of salinity which reduces growth by approximately 10 to $30 \%$. This level of salinity has been estimated to cover as much as $69 \%$ of the Australian wheat belt [32] and is a global problem at this and much higher levels [26].

Seeds were placed on the moist paper towels in petri dishes, closed and double wrapped with polythene bags, and kept under room temperature for 5 to 7 days. Seeds were moisturized every second day. To attain uniform growth, fast growing cotyledons were kept in a cold room for 2 days. Once all the plumules and radicles had reached the length of $3 \mathrm{~mm}$ and $4 \mathrm{~mm}$ respectively the plants were transplanted into the tubes of a supported hydroponics system in a glasshouse. The experiment was conducted in autumn 2008 in both control $(0 \mathrm{mM})$ and saline $(100 \mathrm{mM} \mathrm{NaCl})$ conditions. For the salt stressed plants, the salt was added to the hydroponics at the time of fourth leaf emergence (approximately 12 days after germination) in $25 \mathrm{mM}$ increments and the final concentration of $100 \mathrm{mM}$ was reached as four increments in two days [33]. Five harvests were carried 
out at $15,26,34,40$ and 43 days after planting in the petri dishes. At each harvest time 64 randomly selected plants were imaged and then harvested to measure the shoot fresh weight and shoot dry weight $[34,35]$. This procedure was used in order to provide variations for plant age of plants. The shoot dry weight measurements vary in the range of 0.025-1.67 g with details given in Table 1.

The methods described in this study were also tested on barley dataset. Seven barley cultivars (Clipper, Sahara, Vlamingh, Buloke, CPI 71284, Barque, Golden Promise) were grown in a greenhouse (June/July 2008) in a supported hydroponics system as described by [36]. At the time of third leave emergence, $\mathrm{NaCl}$ was added to the growth solutions of the stress treated plants in $50 \mathrm{mM}$ steps over two days (early morning and late afternoon) to reach a final concentration of $200 \mathrm{mM}$ $\mathrm{NaCl}$. After 20 and 25 days in hydroponics (8 and 13 days after start of salt stress treatment), two side view and one top view images were recorded before shoots were harvested for measuring fresh weight and dry weight. The barley shoot dry weight measurements vary in the range of 0.016-2.25 g with details given in Table 2 .

\section{Image processing algorithm}

We used the LemnaTec 3D Image Analyser (LemnaTec $\mathrm{GmbH}$, Wuerselen, Germany) to run image processing algorithms to extract information from the plant RGB images. The plant color images were first converted into the "Hue Saturation Intensity (HSI)" color model in order to increase the contrast between plant region and background region. A threshold was applied on the hue image in order to separate plant area from the background. The segmentation process was accomplished by selecting the pixels with values over the threshold belonging to plant region and rejecting all the other pixels to the background region. The resulting image is a binary or two-level image, using white and black to distinguish the plant and background regions, respectively.
The number of pixels inside the plant region was counted in each of the three orthogonal views, converted to $\mathrm{mm}^{2}$ using the appropriate calibration factor, and then summed to give the projected shoot area. This is not the actual shoot surface area but the sum of the areas of the image projected in three planes. There are many cases when a mature plant's leaves are overlapping, appearing behind one another in side view images. In these cases, a top view image provides a means of correction of plant area for those overlapping leaves in side view images. The three orthogonal views (two side views from 90 rotational difference) and a top view correct for hidden areas in the other views and give a robust representation of plant area overall.

In addition, the top view camera was located at a distance of $2 \mathrm{~m}$ above the plant, while plant heights were generally much less than $80 \mathrm{~cm}$. Thus, the camera distance is sufficient for the pixel resolution of leaves near the bottom of the plant to be not too different from that for leaves near the top. Also, the analysis using the two side images alone yields slightly worse results, which demonstrates that the top view is indeed useful. A schematic diagram of the image processing procedure is shown in Figure 1.

\section{Cross validation technique}

To measure the generalization or estimation error of a predictive model, the technique of cross validation was used. Cross validation, or rotation estimation, is a technique for assessing the prediction error. This technique estimates the generalization error, $\mathrm{L}(\mathrm{Y}, \hat{\mathrm{Y}})$, where $\mathrm{L}$ is the distance function and $\hat{Y}$ is the model applied to the independent test sample from the distribution of $\mathrm{X}$ and $\mathrm{Y}$. Cross validation is a robust method and preferred over the $R^{2}$ statistic. The main reason is that $R^{2}$ inevitably increases with additional predictors, and more predictors automatically yield improved prediction within one dataset. However, the cross validation error decreases only as long as the additional predictor improves the predictive capability of the model in an independent dataset [37]. In

Table 1 Details of Shoot Dry Weight measurements (wheat dataset)

\begin{tabular}{|c|c|c|c|c|c|c|}
\hline \multirow{2}{*}{$\begin{array}{c}\text { Plant age } \\
\text { (days after planting) }\end{array}$} & \multicolumn{2}{|c|}{ Control plants (no salt) } & \multicolumn{2}{|c|}{ Salt stressed plants } & \multicolumn{2}{|c|}{ Two salt treatments combined } \\
\hline & $\begin{array}{l}\text { SDW } \\
\text { (ave) }\end{array}$ & $\begin{array}{c}\text { SDW } \\
\text { (stdev) }\end{array}$ & $\begin{array}{l}\text { SDW } \\
\text { (ave) }\end{array}$ & $\begin{array}{l}\text { SDW } \\
\text { (stdev) }\end{array}$ & $\begin{array}{l}\text { SDW } \\
\text { (ave) }\end{array}$ & $\begin{array}{l}\text { SDW } \\
\text { (stdev) }\end{array}$ \\
\hline 15 & 0.03 & 0.01 & 0.02 & 0.01 & 0.03 & 0.01 \\
\hline 26 & 0.17 & 0.04 & 0.14 & 0.05 & 0.15 & 0.05 \\
\hline 34 & 0.47 & 0.10 & 0.28 & 0.06 & 0.37 & 0.13 \\
\hline 40 & 0.98 & 0.16 & 0.51 & 0.08 & 0.74 & 0.27 \\
\hline 43 & 1.17 & 0.22 & 0.66 & 0.16 & 0.91 & 0.32 \\
\hline Grand Total & 0.58 & 0.47 & 0.33 & 0.25 & 0.451 & 0.39 \\
\hline
\end{tabular}

The SDW values are given in grams.

SDW = shoot dry weight; ave = average; stdev = standard deviation. 
Table 2 Details of Shoot Dry Weight measurements (barley dataset)

\begin{tabular}{ccccccc}
\hline $\begin{array}{c}\text { Plant age } \\
\text { (days after transplant) }\end{array}$ & \multicolumn{2}{c}{ Control plants } & \multicolumn{2}{c}{ Salt stressed plants } & \multicolumn{2}{c}{ Two salt treatments combined } \\
& $\begin{array}{c}\text { SDW } \\
\text { (ave) }\end{array}$ & $\begin{array}{c}\text { SDW } \\
\text { (stdev) }\end{array}$ & $\begin{array}{c}\text { SDW } \\
\text { (ave) }\end{array}$ & $\begin{array}{c}\text { SDW } \\
\text { (stdev) }\end{array}$ & $\begin{array}{c}\text { SDW } \\
\text { (ave) }\end{array}$ & $\begin{array}{c}\text { SDW } \\
\text { (stdev) }\end{array}$ \\
\hline 20 & 0.124 & 0.040 & 0.096 & 0.045 & 0.110 & 0.044 \\
25 & 0.258 & 0.103 & 0.158 & 0.058 & 0.210 & 0.097 \\
49 & & & 0.763 & 0.599 & 0.763 & 0.599 \\
Grand Total & $\mathbf{0 . 1 9 3}$ & $\mathbf{0 . 1 0 3}$ & $\mathbf{0 . 4 4 9}$ & $\mathbf{0 . 5 3 3}$ & $\mathbf{0 . 3 6 3}$ & $\mathbf{0 . 4 5 4}$ \\
\hline
\end{tabular}

The SDW values are given in grams.

the cross validation technique, the observations are randomly assigned indices, integers 1 to $\mathrm{K}$. In this way, the dataset is partitioned into $\mathrm{K}$ approximately equal-sized parts. Then, the model is fitted to $\mathrm{K}-1$ parts of the dataset (with one part, say the $k^{\text {th }}$ part, removed), and the prediction error of the fitted model is calculated from the $k^{\text {th }}$ part. This procedure is repeated for $k=1,2, . ., \mathrm{K}$ rounds, and estimation errors, such as the root mean square errors (RMSE values), are averaged over the rounds [37-39]. Typical choices of $K$ are 5 or 10 , and in this study fivefold (i.e, $K=5$ ) cross validation was used. The estimation errors obtained from applying this technique were used to compare the performance of different predictive models. The cross validation analysis was performed in Matlab (Mathworks Inc., Natick, MA).

\section{Results and Discussion Model development}

For our data, the linear method for estimating biomass as a linear function of plant area $[14,40]$ performed better than non-linear models, such as quadratic, cubic and power methods as mentioned in $[1,21]$. When quadratic and cubic models were fitted, we found that the higher order coefficients were not significant (Table 3). The coefficients are computed from regression modeling using SPSS software package (version 17, IBM, Chicago, Illinois, USA). The models mentioned in this table were developed using the dataset from 320 plants collected in the experiment explained earlier. In these models the plant biomass, or shoot dry weight, was the dependent variable and the projected shoot area was defined to be independent variable. For instance, the linear model is a function with the equation of SDW $=\mathrm{a}_{0}+\mathrm{a}_{1} \mathrm{~A}$, where $\mathrm{A}$ is the projected shoot area and SDW is the dependent variable shoot dry weight. The equations associated with the quadratic, cubic and power models are SDW $=\mathrm{a}_{0}+\mathrm{a}_{1} \mathrm{~A}+\mathrm{a}_{2} \mathrm{~A}^{2}$, SDW $=\mathrm{a}_{0}+$ $a_{1} A+a_{2} A^{2}+a_{3} A^{3}$ and SDW $=a_{0} A^{a 1}$, respectively.

As can be seen from the Table 3 , among polynomial models, only the linear model is significant. The linear model may be compared with the non-linear power model by inspecting their estimation errors achieved using five fold cross validation analysis applied on the wheat dataset.
Table 4 summarizes the root mean square errors (RMSE) from these two models. The RSME is given by:

$$
\sqrt{\frac{1}{n} \sum_{k=1}^{n}\left(\mathrm{SDW}_{\text {predicted }}-\mathrm{SDW}_{\text {actual }}\right)_{k}^{2}}
$$

where $n$ is the total number of images. The estimation error of the linear method is significantly smaller ( $\mathrm{P}$ value $<0.00005)$ than that from the power method (Table 4).

The linear model seems to be the best of those considered so far, justifying its common use in the literature.

When the data were disaggregated into the two bread wheat cultivars, i.e. Krichauff and Berkut, the linear model was still highly significant and could explain greater than $95 \%$ of the variance of the values observed. Figure 2 shows the scatter plot of actual SDW values and estimated values obtained by using this method under two variety groups.

However, this method achieves a large estimation bias for salt-stressed and non-salt-stressed plants. Using this method where the biomass is estimated as a linear function of plant area, the large estimation bias means that plants under salt stress that have the same area (predicted SDW) as the control plants, would in fact weigh more than control plants (greater actual SDW). In other words, this method systematically under-estimated the SDW of salt stressed plants while systematically overestimating that of plants not under salt stress. An example is illustrated in Figure 3 where example points from two plants under different treatments are highlighted.

Analysis of the scatter plot of actual SDW values compared with the values estimated by the linear method for five plant ages, however, indicated that plants under salt stress which have the same area (predicted SDW) but greater mass than the control plants are in fact older than those salt free plants (Figure 4). This suggests that the bias observed between the salt-stressed and salt free plants is related to plant age. In this analysis, the plant age is measured from the date of planting. 


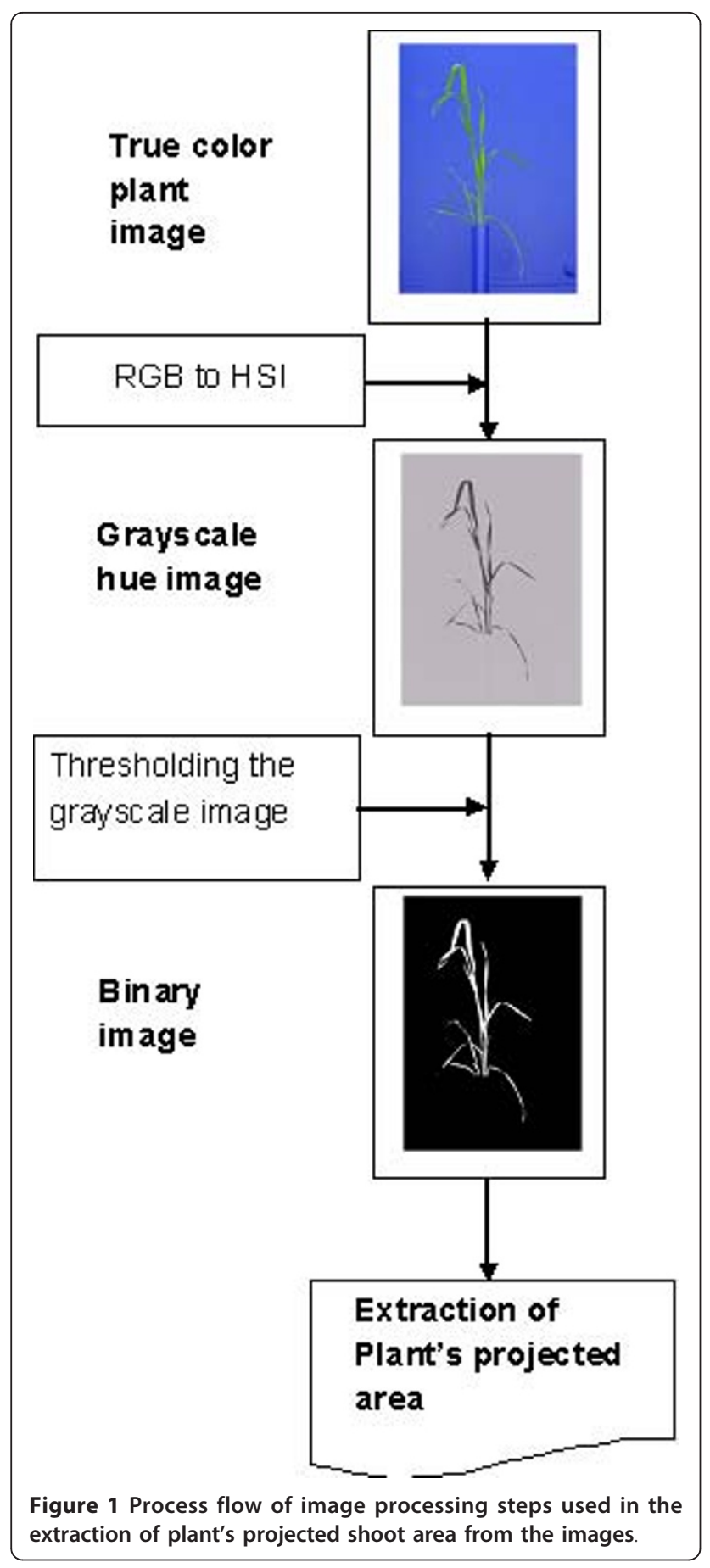

To reduce the bias, we propose a predictive model based on the concept of plant specific weight. The plant specific weight (PSW) is defined as the plant weight per total projected shoot area. The observations across the images showed that PSW can be estimated as a linear function of plant age (Figure 5). Therefore, PSW could be written as a linear form of plant age, i.e. PSW $=b_{0}+$ $b_{1} \times$ plant age.
Table 3 Significance of regression coefficient of different methods used to estimate plant biomass from the plant area

\begin{tabular}{llcccc}
\hline Model & Coefficient & $\begin{array}{c}\text { Coefficient } \\
\text { value }\end{array}$ & $\begin{array}{c}\text { Std. } \\
\text { Error }\end{array}$ & t & Sig. \\
\hline Linear & $a_{0}[\mathrm{~g}]$ & -.043 & .008 & -5.517 & .000 \\
& $a_{1}\left[\mathrm{~g} / \mathrm{mm}^{2}\right]$ & .003 & .000 & 80.412 & .000 \\
\hline Quadratic & $a_{0}[\mathrm{~g}]$ & -.046 & .011 & -3.989 & .000 \\
& $a_{1}\left[\mathrm{~g} / \mathrm{mm}^{2}\right]$ & .003 & .000 & 22.237 & .000 \\
& $a_{2}\left[\mathrm{~g} / \mathrm{mm}^{4}\right]$ & $-1.002 \mathrm{E}-7$ & .000 & -.347 & .729 \\
\hline Cubic & $a_{0}[\mathrm{~g}]$ & -.065 & .015 & -4.231 & .000 \\
& $a_{1}\left[\mathrm{~g} / \mathrm{mm}^{2}\right]$ & .004 & .000 & 11.123 & .000 \\
& $a_{2}\left[\mathrm{~g} / \mathrm{mm}^{4}\right]$ & $-3.153 \mathrm{E}-6$ & .000 & -1.911 & .057 \\
& $a_{3}\left[\mathrm{~g} / \mathrm{mm}^{6}\right]$ & $4.458 \mathrm{E}-9$ & .000 & 1.879 & .061 \\
\hline Power & $a_{0}[\mathrm{log}(\mathrm{g})]$ & $4.072 \mathrm{E}-4$ & .087 & -89.243 & .000 \\
& $a_{1}[\mathrm{log}(\mathrm{g}) / \mathrm{log}$ & 1.348 & .018 & 74.655 & .000 \\
& $\left.\left(\mathrm{~mm}{ }^{2}\right)\right]$ & & & & \\
\hline
\end{tabular}

Our basic model, SDW $=$ Area $\times$ PSW, can be extended to:

$$
\text { SDW }=\mathrm{a}_{0}+\mathrm{a}_{1} \times \text { Area } \times \text { density }
$$

where SDW means Shoot Dry Weight (g), Area means projected shoot area on the image plane $\left(\mathrm{mm}^{2}\right)$, and the density can be estimated as a linear function of plant age as for PSW above, and $\mathrm{a}_{0}$ and $\mathrm{a}_{1}$ are the equation coefficients. It is not necessary that the coefficient $\mathrm{a}_{0}$ be zero.

Our proposed predictive model can be rewritten as shown in Equation 2.

$$
\mathrm{SDW}=\mathrm{c}_{0}+\mathrm{c}_{1} \times \text { Area }+\mathrm{c}_{2} \times \text { Area } \times \mathrm{HD}
$$

where $\mathrm{HD}$ is plant age in days after planting.

The coefficients $c_{0}$ to $c_{2}$ were estimated using regression analysis (Table 5). As can be seen from this table, all of these coefficients contribute significantly to the predicted value of shoot dry weight. In our proposed model, the SDW is a function of two inputs of 'Area' and 'Area $\times$ HD' and the coefficients of this model can be computed from a linear regression model, where the values of 'Area' and 'Area $\times$ HD' are the independent variables and the values of 'SDW' are entered as the dependant variables.

Table 4 Estimation error for linear and power models used to estimate plant biomass

\begin{tabular}{ll}
\hline Plant biomass predictive model & RMSE $(\mathbf{g})$ \\
\hline SDW $=a_{0}+a_{1} A$ & 0.088 \\
SDW $=a_{0} A^{a 1}$ & 0.126 \\
\hline
\end{tabular}

$\mathrm{A}=$ Area. 


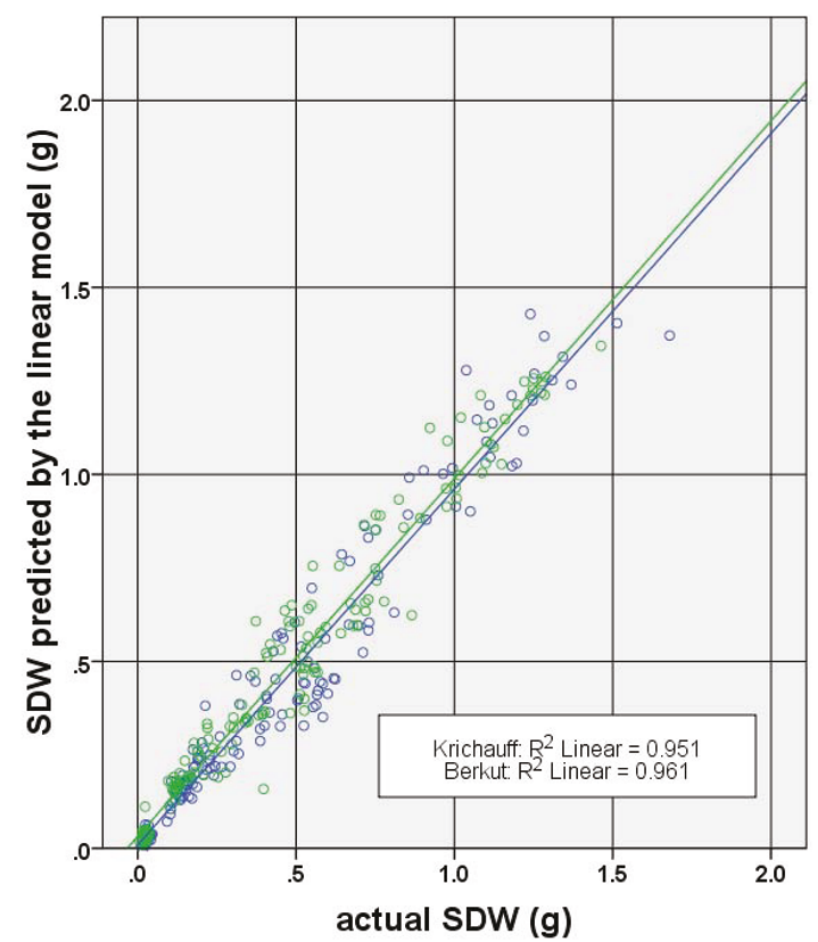

\section{variety}

Q Krichauff

Q Berkut

Figure 2 Scatter plot of the linear method for two wheat varieties. The blue and green lines are the lines of best fit for two cultivar categories.

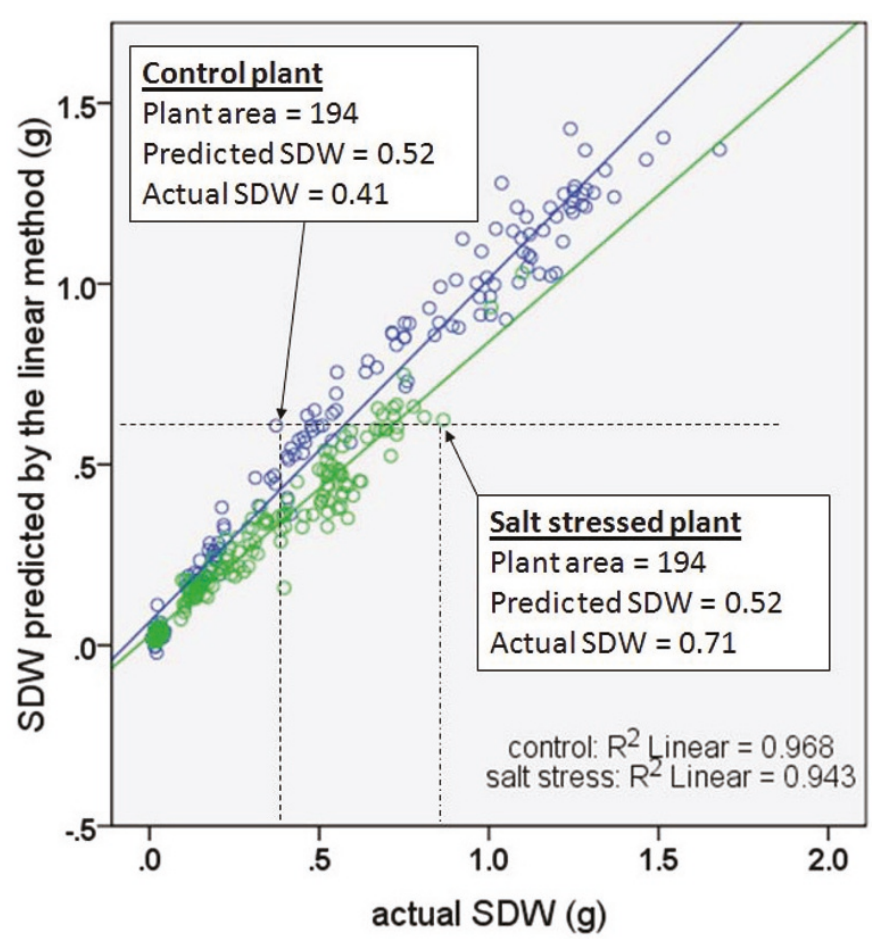

\section{Salt Qcontrol salt stress}

actual SDW (g)

Figure $3 \mathrm{~A}$ scatter plot of actual SDW compared with the estimated values obtained using the linear model for two salt treatment categories. The blue and green lines are the lines of best fit for two salt treatment categories. 


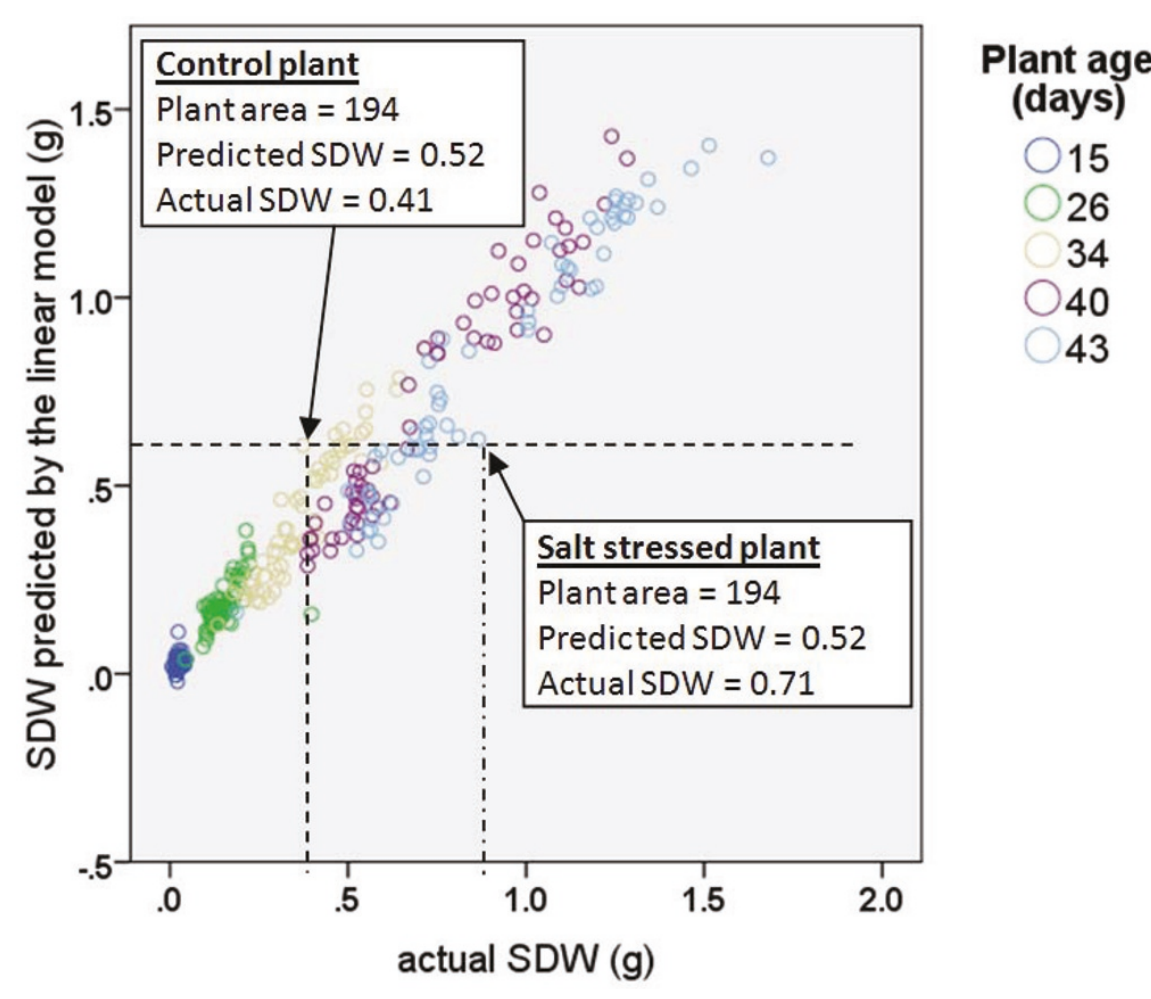

Figure 4 A scatter plot of actual SDW compared with the estimated values obtained using the linear model for five plant age categories.

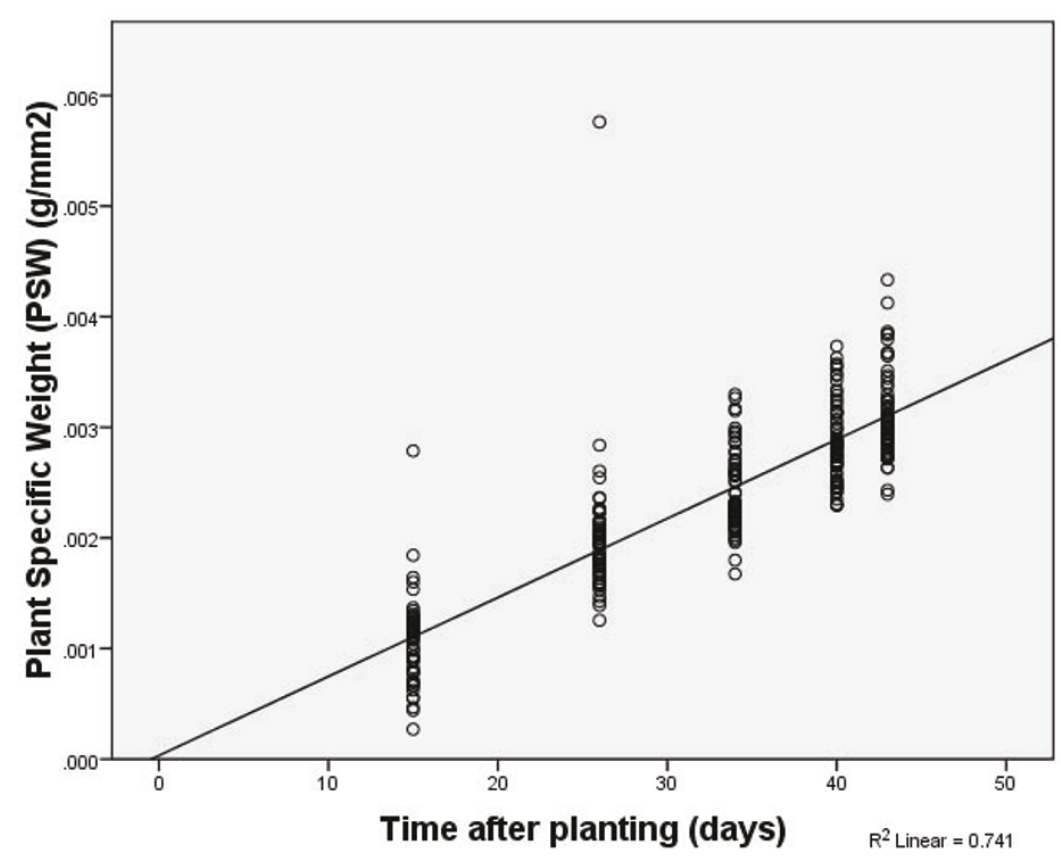

Figure 5 Scatter plot of Plant Specific Weight in terms of time after planting (plant age). A straight line, the line of best fit, seems to describe a plant's PSW in terms of its age. 
Table 5 Significance of regression coefficient of our proposed method

\begin{tabular}{lcccc}
\hline Coefficient & Coefficient value & Std. Error & $\mathbf{t}$ & Sig. \\
\hline$c_{0}[\mathrm{~g}]$ & .054 & .008 & 7.229 & .000 \\
$\mathrm{c}_{1}\left[\mathrm{~g} / \mathrm{mm}^{2}\right]$ & -.001 & .000 & -5.951 & .000 \\
$\mathrm{c}_{2}\left[\mathrm{~g} /\left(\right.\right.$ day. $\left.\left.\mathrm{mm}^{2}\right)\right]$ & $9.866 \mathrm{E}-5$ & .000 & 18.455 & .000 \\
\hline
\end{tabular}

Data analysis and performance comparison of the models As the linear model proved to be better than the nonlinear models we considered, we compared our proposed model with the linear model described in Table 4.

To make it easier to follow, hereafter we refer to the linear model as Model A, and to our proposed model as Model B. The resulting root mean square errors after applying cross validation technique from Model $\mathrm{A}$ and Model B are given in Table 6. Model B produces significantly smaller (P-value < 0.00005) RMSE.

Model B can explain nearly $97 \%$ of the dataset observed in two wheat cultivars (Figure 6). Also, it can be seen that by modeling biomass as a function of plant area and plant age, a small estimation bias or difference between actual and predicted shoot dry weight for salt-stressed and non-salt-stressed plants is obtained (Figure 7). By contrast, the conventional approach of modeling biomass solely as a function of plant area (Model A) resulted in larger estimation bias for salt-stressed and non-salt-stressed plants. The two cases highlighted in Figure 3 are highlighted here in this figure as well.

The estimation errors in terms of RMSE and MTE for either of two treatment categories are given in Table 7. The mean total error (MTE), which is referred to as estimation bias, is the average over all images of $\mathrm{SDW}_{\text {predicted }}-\mathrm{SDW}_{\text {actual }}$. The sign and the magnitude of the MTE indicate whether and how greatly the predicting model under-estimates or over-estimates the SDW value.

Considering two groups of salt treatments, the root mean square estimation error from Model A is about one and one-half times greater than that for Model B for the control plants and salt-stressed plants. Also, the MTE error for Model A is very high - three times higher than that for Model B for the two groups of salt treatments. According to Table 7, on average the linear model over-estimates the weight of a control plant by $35 \mathrm{mg}$ and under-estimates the weight of a stressed plant by $34 \mathrm{mg}$. Considering Table 1 , this estimation

Table 6 Prediction errors obtained from cross validation method for the linear model and the proposed model

\begin{tabular}{ll}
\hline Predictive model & RMSE (g) \\
\hline Model A: SDW $=a_{0}+a_{1} A$ & 0.088 \\
Model B: SDW $=c_{0}+c_{1} A+c_{2} A H$ & 0.058 \\
\hline
\end{tabular}

$\mathrm{A}=$ Area, $\mathrm{H}=$ Plant age error is about $10 \%$ of the mean of all shoot dry weight measurements. Meanwhile, the observations indicate that there is very small bias obtained from Model B to estimate plant biomass. When using the proposed model (Model B), this bias is only $11 \mathrm{mg}$ greater and less than the actual weight of the plant for control and salt stressed plant, respectively.

\section{Validating the model using barley dataset}

Similar observations were achieved by comparing the estimation errors obtained from the linear model (Model A) and the proposed model (Model B) on a series of barley dataset obtained from some selected cultivars. The coefficients of the models were obtained using regression analysis applied on the barley dataset. The models with their regression coefficients and the comparison results in terms of root square of estimation error are given in Table 8 .

As can be seen, the estimation error for Model B is less than that for Model A. Since the salt application was the main source of estimation bias, RMSE errors obtained from two models for two categories of saltstressed and non-stressed plants were also compared. The results of this comparison are given in Table 9. We see that Model B achieves a significantly lower RMSE than that for Model A for control plants and RMSE values were approximately the same for the two models for salt-stressed plants. However, the values of MTE errors indicated that on average Model A over-estimated the shoot dry weight of a non-salt-stressed barley plant $93 \mathrm{mg}$ (i.e. $30 \%$ of the average shoot dry weight of all plants), which is 10 times greater than the error for Model B. Model B also estimated the shoot dry weight of salt-stressed plants only $5 \mathrm{mg}$ less than the actual shoot dry weight. This bias error was about 10 times less than that for the linear model (Model A).

Overall, these results confirmed the idea that the plant age, which was used as an additional input for Model B, plays a key role in reducing the error for estimating the plant biomass. This can be seen graphically in the scatter plots of Figure 8 where two regression lines of two salt treatment categories are much closer together and to the line of the best fit for the total values when our proposed method, i.e. Model B, is applied. In contrast, these regression lines are far apart when the Model A is used to estimate plant shoot dry weight.

\section{Conclusions}

In this study we have presented a method for accurate estimation of plant shoot dry weight from two dimensional images. Our proposed model employs information obtained from the images of plants and their age. This approach provides an accurate and practical model for the estimation of wheat and barley shoot dry weight as 


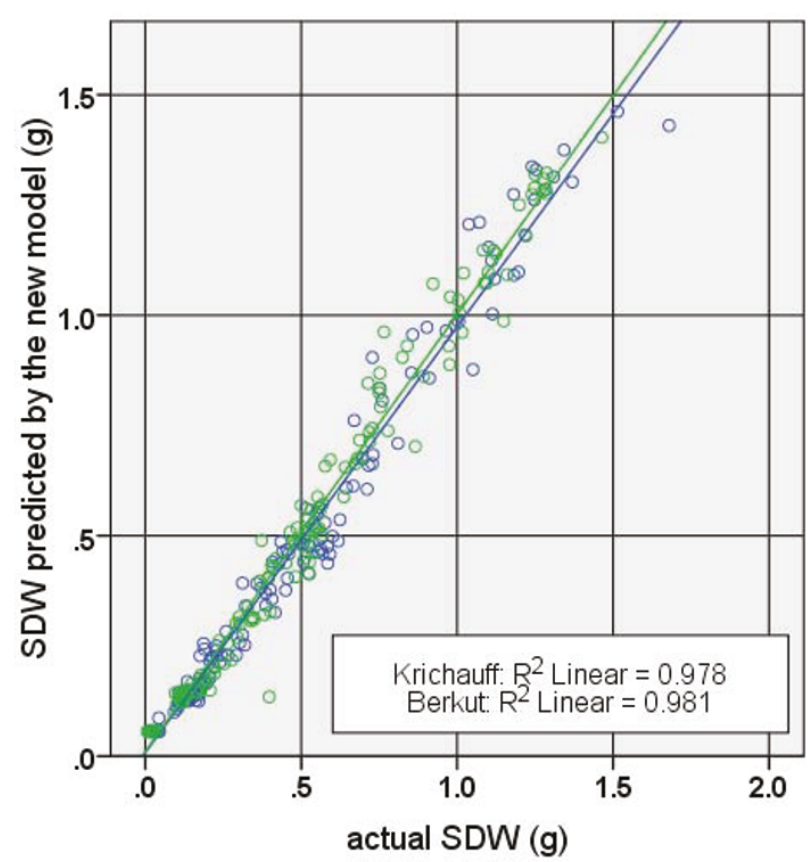

\section{variety}

Krichauff

Berkut

Figure 6 Scatter plots of actual SDW compared with the estimated values obtained using the model proposed in this study for two wheat varieties.

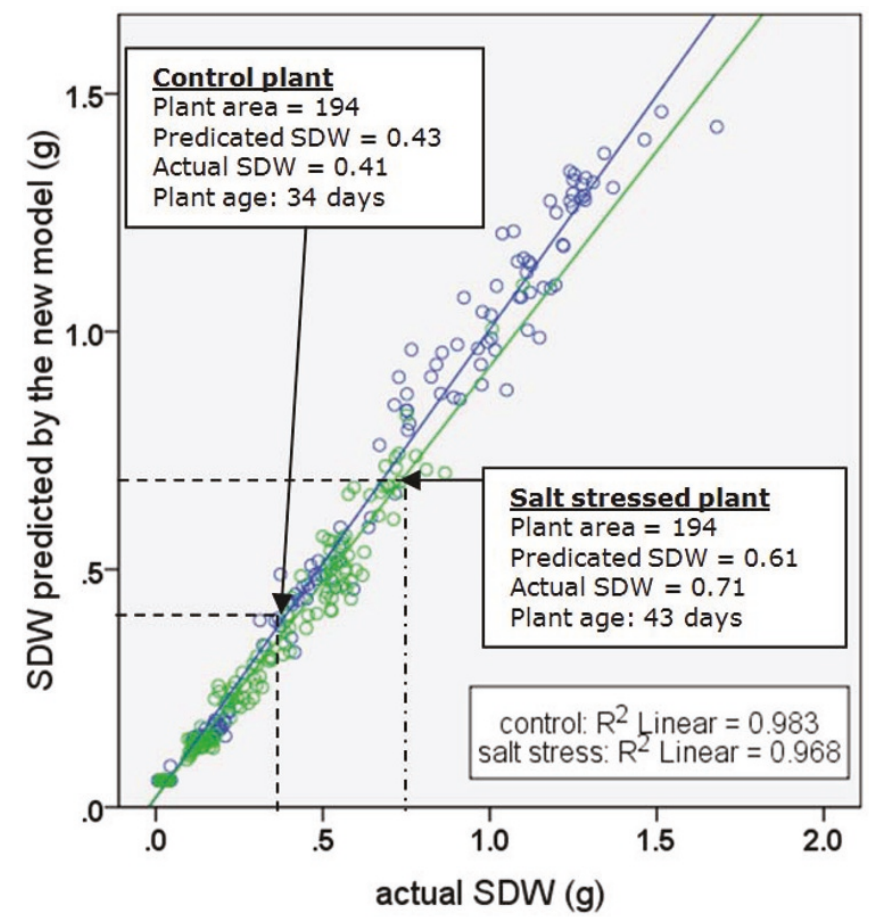

\section{Salt \\ Q control \\ salt stress}

Predicated SDW $=0.61$

Actual SDW $=0.71$

Plant age: 43 days

actualSDW $(\mathrm{g})$

Figure 7 Scatter plots of actual SDW compared with the estimated values obtained using the model proposed in this study for two salt treatment categories. 
Table 7 Mean square estimation error and mean total estimation error (bias) for two models under two salt treatment categories

\begin{tabular}{ccccc}
\hline & \multicolumn{2}{c}{ Model A } & \multicolumn{2}{c}{ Model B } \\
\hline Salt treatment & $\begin{array}{c}\text { RMSE } \\
(\mathbf{g})\end{array}$ & $\begin{array}{c}\text { Bias }(\text { MTE) } \\
(\mathbf{g})\end{array}$ & $\begin{array}{c}\text { RMSE } \\
(\mathbf{g})\end{array}$ & $\begin{array}{c}\text { Bias (MTE) } \\
(\mathbf{g})\end{array}$ \\
\hline control & 0.090 & 0.035 & 0.062 & 0.011 \\
salt stress & 0.076 & -0.034 & 0.052 & -0.011 \\
\hline
\end{tabular}

Table 8 Prediction errors obtained from cross validation method on barley dataset for the linear and proposed models

\begin{tabular}{lll}
\hline Predictive model & Coefficients & $\begin{array}{l}\text { RMSE } \\
(\mathbf{g})\end{array}$ \\
\hline Model A: SDW $=a_{0}+a_{1} A$ & $a_{0}=-0.132 ; a_{1}=0.003 ;$ & 0.136 \\
Model B: SDW $=c_{0}+c_{1} A+$ & $\begin{array}{l}c_{0}=-0.025 ; c_{1}=5.48 E-4 ; c_{2}= \\
5.60 E-5\end{array}$ & 0.105 \\
$C_{2} A H$ & & \\
\hline
\end{tabular}

$\mathrm{A}=$ Area, $\mathrm{H}=$ Plant age.

Table 9 Mean square estimation error and mean total estimation error (bias) for two models under two salt treatment categories for barley dataset

\begin{tabular}{lcccc}
\hline & \multicolumn{2}{c}{ Model A } & \multicolumn{2}{c}{ Model B } \\
\hline & RMSE (g) & Bias (MTE) (g) & RMSE (g) & Bias (MTE) (g) \\
\hline control & 0.143 & 0.093 & 0.032 & 0.009 \\
salt stress & 0.120 & -0.047 & 0.115 & -0.005 \\
\hline
\end{tabular}

a substitute for conventional destructive methods of biomass measurement. We also demonstrated that, for salt stressed plants, the estimation bias between the actual and predicted shoot dry weight values can be overcome to a large extent by using plant biomass estimators with plant age as an additional input. Without this method, we cannot accurately infer the plant biomass for salt stressed plants. We tested our proposed model on wheat and barley from different contrasted varieties and under salt stress and found out that with our method the error in biomass estimation was reduced significantly. Thus, our method enables high throughput nondestructive estimation of biomass for cereal plants under salt stress and may possibly do so for other types of plants and stresses.

\section{Acknowledgements}

The authors are thankful to Mr. James Eddes for creating the image analysis routines in LemnaTec software. This research was supported by the Government of South Australia through the Premier's Science and Research Fund. We also appreciate Dr Juergen Zanghellini for his valuable comments on the final version of the manuscript.

\section{Author details}

'Phenomics and Bioinformatics Research Centre, Australian Centre for Plant Functional Genomics, School of Mathematics and Statistics, University of South Australia, Mawson Lakes, SA, 5095, Australia. ${ }^{2}$ School of Mathematics and Statistics, University of South Australia, Mawson Lakes, SA, 5095, Australia. ${ }^{3}$ Australian Centre for Plant Functional Genomics, University of Adelaide, Glen Osmond SA 5064, Australia. ${ }^{4}$ Department of Computer Science and Center for Computational and Integrative Biology, Rutgers University, Camden, NJ 08102, USA.

\section{Authors' contributions}

$\mathrm{KR}$ and $\mathrm{BB}$ performed the laboratory work, acquisition and processing of the image data. SR, MT and DSL supervised the study. MRG developed the concept of new model, carried out the data analysis and interpretations, and wrote the manuscript. DSL and RAF contributed to conceiving the study and assisted in data analysis and also in writing the manuscript. All authors contributed in reading, editing and approving the final manuscript.

\section{Competing interests}

The authors declare that they have no competing interests.

Received: 11 October 2010 Accepted: 1 February 2011

Published: 1 February 2011

\section{References}

1. Tackenberg O: A new method for non-destructive measurement of biomass, growth rates, vertical biomass distribution and dry matter
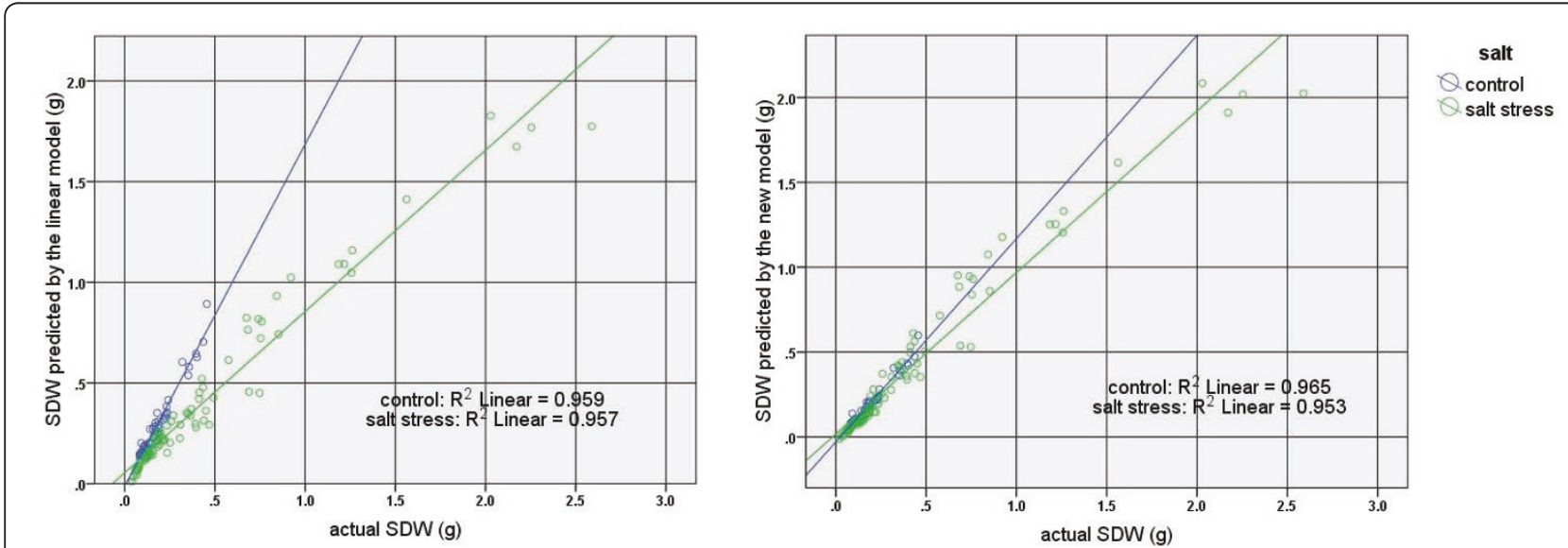

Figure 8 Scatter plots of actual barley shoot dry weight values compared with the estimated shoot dry weight values obtained from Model A (left) and the Model B (right) under two salt treatment categories. 
content based on digital image analysis. Annals of Botany 2007, 99:777-783.

2. Niklas KJ, Enquist BJ: On the Vegetative Biomass Partitioning of Seed Plant Leaves, Stems, and Roots. The American Naturalist 2002, 159:482-497.

3. Poorter $\mathrm{H}$, Nagel $\mathrm{O}$ : The role of biomass allocation in the growth response of plants to different levels of light, $\mathrm{CO}^{2}$, nutrients and water: a quantitative review. Functional Plant Biology 2000, 27:595-607.

4. Wilson PJ, Thompson K, Hodgson JG: Specific Leaf Area and Leaf Dry Matter Content as Alternative Predictors of Plant Strategies. New Phytologist 1999, 143:155-162

5. Wheeler WRCCJ: Estimating plant biomass: A review of techniques. Austral Ecology 1992, 17:121-131.

6. Plant Accelerator. [http://www.plantaccelerator.org.au/].

7. High Resolution Plan Phenotyping Centre. [http://www.plantphenomics. org.au/HRPPC].

8. The Leibniz Institute of Plant Genetics and Crop Plant Research (IPK) [http://www.ipk-gatersleben.de].

9. Institute of Biological, Environmental and Rural Sciences (IBERS). [http:// www.aber.ac.uk/en/ibers/].

10. French National Institute for Agricultural Research (INRA). [http://www. international.inra.fr/].

11. Nilsson H: Remote Sensing and Image Analysis in Plant Pathology. Annual Review of Phytopathology 1995, 33:489-528.

12. Montès N, Gauquelin T, Badri W, Bertaudière V, Zaoui EH: A nondestructive method for estimating above-ground forest biomass in threatened woodlands. Forest Ecology and Management 2000, 130:37-46.

13. Lim KS, Treitz PM: Estimation of above ground forest biomass from airborne discrete return laser scanner data using canopy-based quantile estimators. Scandinavian Journal of Forest Research 2004, 19:558-570.

14. Dietz H, Steinlein T: Determination of plant species cover by means of image analysis. Journal of Vegetation Science 1996, 7:131-136.

15. Sher-Kaul S, Oertli B, Castella E, Lachavanne JB: Relationship between biomass and surface area of six submerged aquatic plant species. Aquatic Botany 1995, 51:147-154.

16. Rutchey K, Schall T, Sklar F: Development of Vegetation Maps for Assessing Everglades Restoration Progress. Wetlands 2009, 28:806-816.

17. Rutchey K, Vilchek L: Air Photointerpretation and Satellite Imagery Analysis Techniques for Mapping Cattail Coverage in a Northern Everglades Impoundment. Photogrammetric Engineering and Remote Sensing 1999, 65:185-191.

18. Lu D, Mausel P, Brondizio E, Moran E: Aboveground biomass estimation of successional and mature forests using TM images in the Amazon Basin. In Advances in Spatial Data Handling. Edited by: Richardson D, Oosterom Pv. New York: Springer-Verlag; 2002:183-196.

19. Seelan SK, Laquette S, Casady GM, Seielstad GA: Remote sensing applications for precision agriculture: A learning community approach. Remote Sensing of Environment 2003, 88:157-169.

20. Lamb DW, Brown RB: Precision Agriculture: Remote-Sensing and Mapping of Weeds in Crops. Journal of Agricultural Engineering Research 2001, 78:117-125.

21. Paruelo JM, Lauenroth WK, Roset PA: Estimating Aboveground Plant Biomass Using a Photographic Technique. Journal of Range Management 2000, 53:190-193.

22. Mizoue N, Masutani T: Image analysis measure of crown condition, foliage biomass and stem growth relationships of Chamaecyparis obtusa. Forest Ecology and Management 2003, 172:79-88.

23. Lukina EV, Stone ML, Raun WR: Estimating vegetation coverage in wheat using digital images. Journal of Plant Nutrition 1999, 22:341-350.

24. Smith SM, Garrett PB, Leeds JA, McCormick PV: Evaluation of digital photography for estimating live and dead aboveground biomass in monospecific macrophyte stands. Aquatic Botany 2000, 67:69-77.

25. Smith MAL, Spomer LA, Meyer MJ, McClelland MT: Non-invasive image analysis evaluation of growth during plant micropropagation. Plant Cell, Tissue and Organ Culture 1989, 19:91-102.

26. Munns R, Tester M: Mechanisms of salinity tolerance. Annual Review of Plant Biology 2008, 59:651-681.

27. Skirycz A, Inzé D: More from less: plant growth under limited water. Current Opinion in Biotechnology 2010, 21:197-203.

28. Maas EV, Poss JA: Salt sensitivity of wheat at various growth stages. Irrigation Science 1989, 10:29-40.
29. Madhava Rao KV, Raghavendra AS, Janardhan Reddy K, Springer-Verlag: Physiology and molecular biology of stress tolerance in plants Dordrecht: Springer; 2006

30. Fricke W, Akhiyarova G, Wei W, Alexandersson E, Miller A, Kjellbom PO, Richardson A, Wojciechowski T, Schreiber L, Veselov D, et al: The shortterm growth response to salt of the developing barley leaf. J Exp Bot 2006, 57:1079-1095.

31. Genc Y, Oldach K, Verbyla A, Lott G, Hassan M, Tester M, Wallwork H, McDonald G: Sodium exclusion QTL associated with improved seedling growth in bread wheat under salinity stress. TAG Theoretical and Applied Genetics 2010, 121:877-894.

32. Rengasamy P: Transient salinity and subsoil constraints to dryland farming in Australian sodic soils: an overview. Australian Journal of Experimental Agriculture 2002, 42:351-361.

33. Rajendran K, Tester M, Roy SJ: Quantifying the three main components of salinity tolerance in cereals. Plant, Cell \& Environment 2009, 32:237-249.

34. Garnier E, Shipley B, Roumet C, Laurent G: A Standardized Protocol for the Determination of Specific Leaf Area and Leaf Dry Matter Content. Functional Ecology 2001, 15:688-695.

35. Cornelissen JHC, Lavorel S, Garnier E, Diaz S, Buchmann N, Gurvich DE, Reich PB, ter Steege H, Morgan HD, van der Heijden MGA, et al: A handbook of protocols for standardised and easy measurement of plant functional traits worldwide. Australian Journal of Botany 2003, 51:335-380.

36. Genc Y, McDonald GK, Tester M: Reassessment of tissue Na+ concentration as a criterion for salinity tolerance in bread wheat. Plant, Cell \& Environment 2007, 30:1486-1498.

37. Hastie T, Tibshirani R, Friedman JH: The elements of statistical learning: data mining, inference, and prediction New York: Springer; 2001.

38. Witten $\mid \mathrm{H}$, Frank E: Data mining: practical machine learning tools and techniques. 2 edition. San Francisco, Calif.: Morgan Kaufman; 2005.

39. Hastie T, Tibshirani R, Friedman JH: The elements of statistical learning: data mining, inference, and prediction. 2 edition. New York: Springer; 2009

40. Leister D, Varotto C, Pesaresi P, Niwergall A, Salamini F: Large-scale evaluation of plant growth in Arabidopsis thaliana by non-invasive image analysis. Plant Physiology and Biochemistry 1999, 37:671-678.

doi:10.1186/1746-4811-7-2

Cite this article as: Golzarian et al:: Accurate inference of shoot biomass from high-throughput images of cereal plants. Plant Methods 2011 7:2.

\section{Submit your next manuscript to BioMed Central and take full advantage of:}

- Convenient online submission

- Thorough peer review

- No space constraints or color figure charges

- Immediate publication on acceptance

- Inclusion in PubMed, CAS, Scopus and Google Scholar

- Research which is freely available for redistribution

Submit your manuscript at www.biomedcentral.com/submit
C) Biomed Central 